University of St. Thomas, Minnesota

UST Research Online

$2-2001$

\title{
Psychological Adjustment of Siblings to a Child with Diabetes
}

Colin F. Hollidge

cfhollidge@stthomas.edu

Follow this and additional works at: https://ir.stthomas.edu/ssw_pub

Part of the Clinical and Medical Social Work Commons, and the Social Work Commons

This Article is brought to you for free and open access by the School of Social Work at UST Research Online. It has been accepted for inclusion in Social Work Faculty/Staff Publications by an authorized administrator of UST

Research Online. For more information, please contact asle4660@stthomas.edu. 


\section{PSYCHOLOGICAL ADJUSTMENT OF SIBLINGS TO A CHILD WITH DIABETES}

\section{Colin Hollidge}

This article presents results of a study examining the psychological adjustment of well child siblings living in the same household as siblings with diabetes. A sample of 28 well siblings between the ages of eight and 12 were studied. Psychological adjustment was assessed by measuring self-concept, behavioral difficulties and competence, anxiety, and depression on standardized tests. A semistructured interview reported data gathered on the well siblings' emotional feelings and their communication patterns. The well siblings demonstrated. significant internal psychological stressors and maintained high levels of behavional competence. The internal stressors orizinated from anxiety and low self-concept. Recommendations based on the findings are offered to professionals who work with children with diabetes and their families.

\section{Key words}

diabetes

family illness

sibling adjustment

sibling relationships
A growing body of literature acknowledges the influence siblings have on each other's emotional development. The introduction of a chronic illness into this relationship complicates its negotiations. The chronic illness of one child introduces stressors into the sibling relationship, which may interfere with the psychological growth of the well sibling.

There is a growing interest in studying the effects of a chronically ill child on family members. Because of the success of modern medicine, many children handicapped with illness are living longer and with their families. According to Derouin and Jessee (1996), 10 percent of children in the United States grew up with a brother or sister who suffered from a chronic illness. Most research on the psychosocial adjustment of family members to a child's illness focused on the ill children and their parents rather than healthy siblings (Bendor, 1990; Bluebond-Langer, 1996; Brody \& Stoneman, 1990; Carlson, Leviton, \& Mueller, 1993; Fetrari, 1984; Gogan \& Koocher, 1977; Iles, 1979; Kramer, 1981; McKeever, 1983; Seligman, 1987). Research identifies well siblings as a population at risk of psy* chological distress. Several studies suggest that many well sib lings develop higher risks of anxiety, depressive symptoms, and somatic complaints and suffer from lower self-esteem (Binger, 1973; Bluebond-Langer, 1996; Cairns \& Clark, 1979; Daniels, Miller, Billings, \& Moos, 1986; Ferrari, 1984, 1987; McKeever, 1983; Spinnetta, 1981. In explaining the presence of these stressors in well children living with ill siblings, semistructured interviews suggest that the well sibling's experience of resentment toward the ill child, exaggerated sibling rivalry, strong sense of responsibility, and social and emotional isolation may be contributing factors (Bendor, 1990; Bluebond-Langner, 1996; Chesler, Allswede, \& Caeran, 1991; Crain, Sussman, \& Weil, 1966; Davies, 1993; Tritt \& Esses, 1988).

The study discussed in this article investigated well children living with a child sibling diagnosed with diabetes. Juvenile diabetes is the most frequently reported chronic childhood disease in the United States. Approximately 1.7 per 1,000 children develops diabetes in the United States. There are approximately 13,000 new cases of juvenile diabetes each year

Reproduced with permission of the copyright owner. Further reproduction prohibited without permission. 
(National Institutes of Health, 1995). The vast majority of children who are diagnosed with diabetes suffer from Type I diabetes. This results from the body's failure to produce insulin, a hormone that unlocks the cells of the body, which allows glucose to enter and fuel cells. Insulin does not cure the disease but prevents the disease from causing ongoing damage to the body. Untreated diabetes can lead to blindness, heart problems, strokes, nerve damage, amputation, and kidney failure. Because diabetes is life threatening, daily monitoring of the child's injections, diet, and blood sugar levels is necessary to prevent diabetes from becoming life threatening.

Few studies have investigated the well sibling who lives with a child diagnosed with diabetes. Ferrari (1984) investigated a sample of well sib lings who lived with children diagnosed with a pervasive developmental disability or diabetes and children who served as a control group with no chronic illness. His study concluded that well siblings living with a sibling with diabetes are four times more likely to complain of psychosomatic symptoms as controls and have lower self-concept. scores. Crain et al. (1966) concluded in their study of children with diabetes and their families that well siblings bear the greatest burden of stress in the family. Researchers note that because of the demands of the illness, well siblings are handicapped in the race for parental attention and affection. Wysocki, Huxtable, Linscheid, and Wayne (1989) in a study that focused on diabetes mellitus in preschoolers and their relationships with their mothers suggested that mothers are under a great deal of emotional stress trying to keep up with the rigorous schedule and demands characteristic of children with this illness. Tritt and Esses (1988) empirically observed healthy brothers and sisters who had siblings suffering from either diabetes, juvenile rheumatoid arthritis, or gastrointestinal disease. The authors commented that well children who lived with siblings with diabetes were far more likely to develop psychosomatic symptoms. The authors also concluded that these children had difficulties with social isolation from peers, communication with parents, and resentment toward their sick sibling and felt a sense of personal responsibility toward the ill child.

Recent studies focusing on well siblings living with chronically ill children identified adjustment difficulties. Derouin and Jessee (1996) conducted an exploratory study of healthy siblings living with children who had either asthma or cystic fibrosis.
Forty-two percent of the children investigated felt that the sick child received more attention from parents. Eleven percent of the asthma group and 40 percent of the cystic fibrosis group reported themselves as "feeling the most disturbed or being the most unhappy members of the family" (p. 142).

Zelter and his colleagues (1996) studied how siblings living with children diagnosed with cancer differed from siblings living with healthy children. Two hundred and fifty-four subjects and matched controls were selected from seven oncology pediatric treatment centers throughout the United States. Well siblings reported more problems in somatization scores than the control group. On the Child Behavioral Checklist (Achenbach, 1991), parents scored well siblings in the clinical range on the somatization scale. The investigators reported a significant relationship between well siblings" feelings that "no one cared about them" and the siblings' physical symptoms. According to the investigators children used somatic concerns as an attempt to signal support and nurturance from parents.

Bluebond-Langer (1996) investigated families in which a child was diagnosed with cystic fibrosis. The author interviewed 175 families, conducting extensive field studies on 40 families. The author observed that as the child's disease progressed so did the well sibling's adjustment difficulties. The study suggested that as the illness in children progressed well siblings received less attention from their parents. Parents reported that well siblings bid for attention by feigning illness, asking for medication, disrupting the ill child's physiotherapy, and engaging in disruptive behavior. BluebondLanger stated that somatic behavior occurred because "being sick is an acceptable reason for claiming extra attention and special privileges" (p. 26). Another conclusion drawn from the study suggested that communication between the well sib. lings and their parents decreased as the ill child's health worsened. The author noted that as the sick child's health deteriorated, the well sibling's responsibility toward the ill child increased, often interfering with regular routines. Parents reported that well siblings had too much responsibility for the sick child's care.

Research supports the notion that the introduction of chronic illness to the sibling relationship produces adjustment difficulties. Studies suggest that well siblings may suffer from emotional distress and adaptive challenges because of 
complicated sibling negotiations and parental demands from the illness. Only a few studies have been done that investigated well siblings living with a child who has diabetes. More research is necessary to understand how the unique qualities of this illness affect the well sibling's adjustment.

\section{METHOD}

\section{Purpose}

The purpose of this study was to investigate the psychological experience of well children living in the same household as child siblings with diabetes. The investigator attempted to learn about the well children's degree of psychological stress and sense of well-being by collecting data on standardized tests and through semistructured interviews. The well sibling's adjustment was made operational by behavior, self-concept, anxiety, and depression. These areas were scored by selected standard tests. The semistructured interview was used to assess psychological stressors and well children's subjective experiences of living with a sibling with diabetes.

\section{Sample}

The purposive sample identified children from families who attended a juvenile diabetic clinic in southern Ontario, Canada, in fall 1994. All families in the community who had a child that suffered from juvenile diabetes were treated at the juvenile diabetic clinic. Families who participated in the study had used the clinic's services for at least three months. The range of family involvement at the clinic was from six months to nine years. Eligibility was determined from a form that potential participants' mothers or fathers received at the clinic while attending with their ill child for their regular physical examination. The eligibility criteria included the following:

$\exists$ The child had a diagnosis of juvenile diabetes that was at least three months old.

a The child with diabetes was free from any other chronic illness or disability.

a There was a well sibling between the ages of eight and 12.

a The child with diabetes was insulin dependent.

3 The well child was the closest sibling in age to the sibling with diabetes.

All well children who participated in the study had a sibling that was insulin dependent, hospitalized at least once, and required daily monitoring of diet and insulin injections.
The sample consisted of 28 well children between the ages of eight and 12. The average age of well siblings was 10.3 years. Eight of the well siblings were younger than their sibling with diabetes, and 20 were older. Fifteen of the well siblings were female and 13 were male. Twenty-one well siblings came from intact families, whereas seven came from single-parent families. The average number of children in the family was 2.64 .

\section{Measurement}

There were two types of measurement in this research project-standardized tests and a semistructured interview. I used the Achenbach Child Behavioral Checklist (1991) to measure the well siblings behavioral functioning. Parents scored the checklist. The checklist measured both competence and problematic behavior. The PiersHarris Children's Self-Concept Scale (Piers, 1984) was used to measure self-concept of well siblings. The Reynolds Child Depression Scale (1989) was used to measure well children's degree of depression. Anxiety was measured by the Revised Children's Manifest Anxiety Scale (Reynolds \& Richmond, 1985). These scales where chosen because of their excellent psychometric properties and their use in research with children (Achenbach, 1991; Piers, 1984; Reynolds, 1989; Reynolds \& Richmond, 1985). The Piers-Harris Children's Self-Concept Scale (Cairns \& Clark, 1979; Ferrari, 1984, 1987) and the Achenbach Child Behavioral Checklist (Dyson, Edgar, \& Crnic, 1989; Ferrari, 1984; Lavigne, Traisman, Mars, \& Chashoff, 1982) have been used in earlier research that investigated well siblings living with ill siblings. A major criticism of earlier research emphasized that data were collected from teachers or parents instead of the well siblings themselves (Bluebond-Langer, 1996; Bresleau \& Prabucki, 1987; Daniels \& Moos, 1987; Tritt \& Esses, 1988). The Piers-Hatris Children's Self-Concept Scale, the Reynolds Child Depression Scale, and the Revised Children's Manifest Anxiety Scale are all self-reporting instruments.

Personal scores for all children were compared with the normative scale provided by the Achenbach Child Behavioral Checklist, Piers-Harris Children's Self-Concept Scale, Reynolds Child Depression Scale, and the Revised Children's Manifest Anxiety Scale. For the Piers-Harris Children's Self-Concept Scale and the Revised Children's Manifest Anxiety Scale, stanine scores and ipsative interpretations were used. Stanine scores have been 
used to determine whether subscale scores fall above or below the mean of a normative sample. Ipsative interpretations determine whether a child has significant areas of strength or weakness in one of the subscale areas.

A semistructured interview gathered descriptive data organized around 20 questions. The focus of the interview was on well siblings' feelings about living with a sibling with diabetes, the expression of worry about health, and communication patterns. Variables taken from each section of the interview were scored on a four-point scale. To ensure reliability a coding manual for the semistructured interview was developed and closely followed. An interrater reliability check was performed for each question. Only one question, "worry about health of other family members," received a correlation coefficient that was not within the significant range $(p<.05)$.

\section{Findings}

\section{Results of Structured Tests}

The Revised Children's Manifest Anxiety Scale demonstrated that these children reported moderate to high levels of anxiety (Table 1). For total anxiety, the sample fell primarily in the moderate or high levels of anxiety. The cluster of worry and sensitivity showed the highest mean stanine score and the highest mean ipsative score, suggesting that the symptom of worry and sensitivity constituted the most common and difficult symptom of anxiety.

The results of the Piers-Harris Children's SelfConcept Scale (Table 2) demonstrated that almost half of the well siblings fell below the mean score for total self-concept. Low stanine scores were reported for the cluster of anxiety, whereas the stanine scores of happiness, physical appearance, and intellectual status were all above the mean. Low values for the cluster of anxiety on the ipsative scores demonstrated that anxiety was the most problematic cluster affecting the individual's selfconcept.

The Reynolds Child Depression Scale had a mean $t$ score of 55.03 , suggesting that the children exhibited some depressive symptoms but had no apparent clinically depressive symptoms. The Achenbach Child Behavioral Checklist demonstrated that well children's total competence scores fell very close to the highly competent level (Table 3). Well children exhibited problerns within the total internalizing problem orientation. The subscales of withdrawal, somatic, and anxious/ depressed contributed evenly to this internalizing

Table 1. Scores Revised Children's Manifest Anxiety Scale

\begin{tabular}{|c|c|c|c|c|c|c|}
\hline \multirow{2}{*}{ Mean $/$ score } & \multirow[b]{2}{*}{$s D$} & Minimal & \multicolumn{2}{|c|}{ Moderate } & \multicolumn{2}{|c|}{ High } \\
\hline & & $\%$ & $n$ & $\%$ & $n$ & $\%$ \\
\hline 83.99 & 6.76 & 4.3 & 15 & 53.6 & 9 & 32.1 \\
\hline
\end{tabular}

Stanine Scores for Clusters

\begin{tabular}{|c|c|c|c|c|c|c|c|}
\hline \multirow[b]{2}{*}{ Clustar } & \multirow{2}{*}{ Mean stanine } & \multirow{2}{*}{$S D$} & \multicolumn{2}{|c|}{ Low statine } & & \multicolumn{2}{|c|}{ High stanine } \\
\hline & & & $n$ & $\%$ & & $n$ & $\%$ \\
\hline Phystology & 10.27 & 2.81 & 11 & 39.3 & & 17 & 60.7 \\
\hline Worry and sensitivy & 12.27 & 2.59 & 5 & 17.9 & & 23 & 82.1 \\
\hline Soctal concen & 9.05 & 2.23 & 16 & 57.1 & & 12 & 429 \\
\hline
\end{tabular}

Tpsative Scores for Clusters

\begin{tabular}{|c|c|c|c|c|c|}
\hline \multirow[b]{2}{*}{ Rank } & \multirow[b]{2}{*}{ Cluster } & \multirow[b]{2}{*}{ Ipsative $M$} & \multirow[b]{2}{*}{$S D$} & \multicolumn{2}{|c|}{$\begin{array}{l}\text { Statistically significant } \\
\text { subjects }(\hat{N}=28)\end{array}$} \\
\hline & & & & Positive & Negative \\
\hline 1 & social concerr & -1.43 & 1.56 & 3 & 0 \\
\hline 2 & physiology & -0.20 & 2,03 & 0 & 2 \\
\hline 3 & worry and sensitjvity & 1.71 & 1.47 & 0 & 6 \\
\hline
\end{tabular}


Table 2. Scores of Well Siblings on Pler Harrls Children's Self-Concept Scte

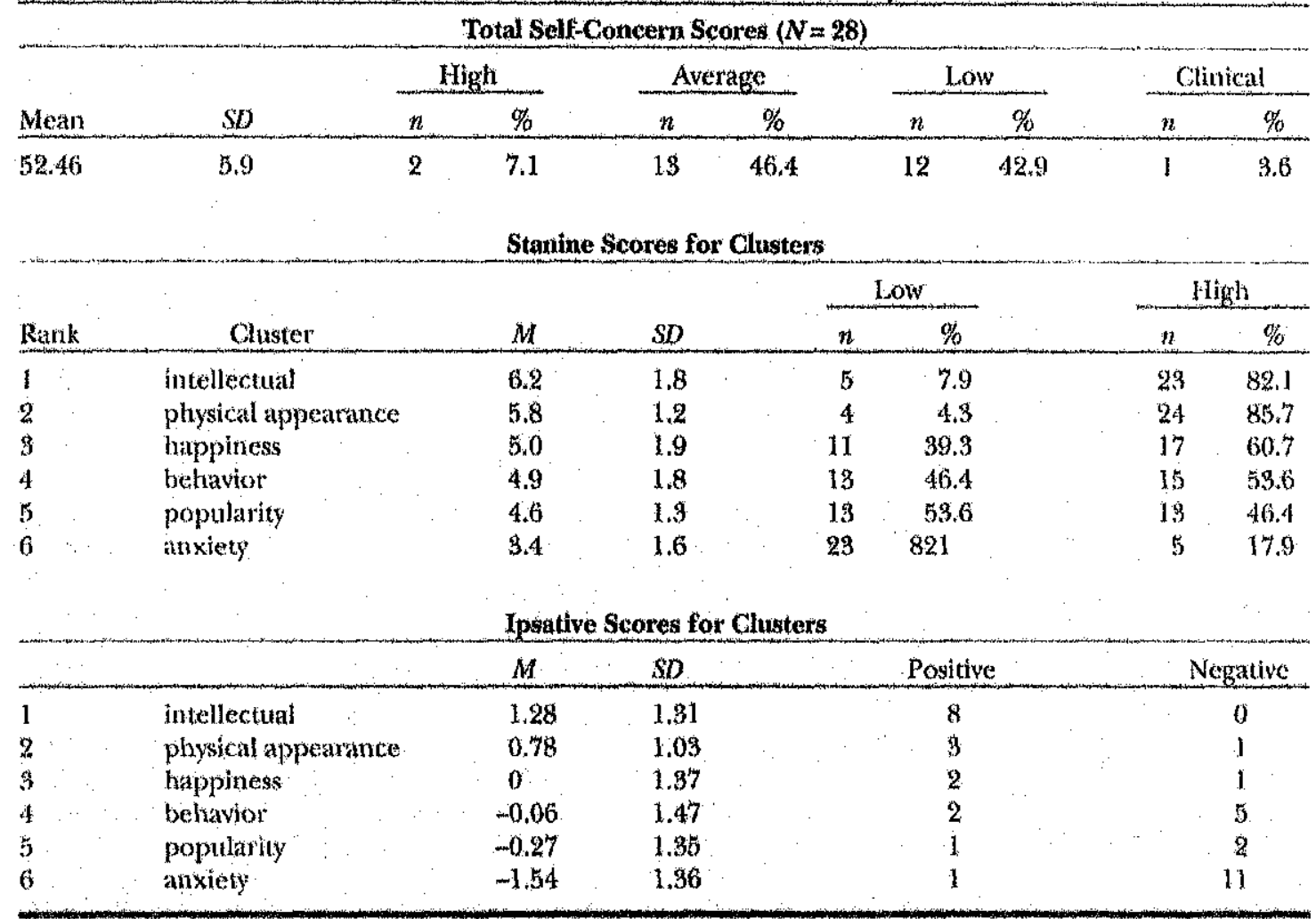

pattern. Mean scores for total externalizing problem orientation suggest that there were very few problems in these clusters.

\section{Results of the Semistructured Interview}

The Well Child's Feelings about Living with a Diabetic Sibling. The semistructured interview exam- ined the degree of affect expressed by well siblings toward their siblings with diabetes. The emotions focused on in the interview were responsibility, unhappiness, jealousy, competition, negativity, shame, and guilt. The majority of well siblings exhibited feelings of responsibility that demonstrated internal expectations centered on being protectors

Tabla 3. Competence Scores and Internal Probiem Orlentation Scores on the Achenbach Child Behavior Cheokllst $(N=28)$

\begin{tabular}{|c|c|c|c|c|c|c|c|c|}
\hline \multirow[b]{2}{*}{ Cluster } & \multirow[b]{2}{*}{ Mean $t$} & \multirow{2}{*}{ SD } & \multicolumn{2}{|c|}{ High } & \multicolumn{2}{|c|}{ Average } & \multicolumn{2}{|c|}{ Ctinical } \\
\hline & & & $n$ & $\%$ & $n$ & $\%$ & $n$ & $\%$ \\
\hline Total competence & 49.2 & 8.0 & 13 & 46.4 & 13 & 46.4 & 2 & 7.1 \\
\hline Activity & 49.0 & 4.7 & 13 & 46.4 & 14 & 50.0 & 1 & 3.5 \\
\hline Soctal & 46.3 & 8.2 & 12 & 42.8 & 10 & 35.7 & 6 & 21.4 \\
\hline School & 51.1 & 8.7 & 19 & 42.8 & 8 & 28.5 & 1 & 3.5 \\
\hline Total problem orientation & 56.6 & 6.2 & 14 & 50,0 & 7 & 25.0 & 7 & 25.0 \\
\hline Total internal problem orientation & 62,2 & 6.6 & 3 & 10.7 & 8 & 28.5 & 17 & 60.7 \\
\hline Withdritwal & 60.5 & 6.1 & 11 & 39.1 & 11 & 39.1 & 6 & 21.4 \\
\hline Somatic complaints & 60.8 & 6.8 & 14 & 50.0 & 9 & $32.4:$ & 5 & 17.8 \\
\hline Anxious/depressed & 60.7 & 6.0 & 11 & 39.2 & 12 & 42.8 & 5 & $1 \% .8$ \\
\hline
\end{tabular}

Reproduced with permission of the copyright owner. Further reproduction prohibited without permission. 
and caregivers toward their ill brothers and sisters. This 9-year-old boy demonstrated his high expectation of responsibility:

I make sure when I am with him that I get stuff that does not have sugar in it so that it does not tempt him. I sometimes have to tell him when we are alone not to eat sugar . . . sometimes I tell Mom, and he gets angry and hits me. I don't mind because I know he's just mad at the diabetes. If he

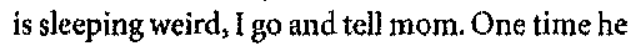
was tired and dropped off to sleep and he had to go to the hospital. Now I watch him to make sure that he's not sleeping like that.

The well siblings experienced themselves as being the unhappiest about their sibling's diabetes, after their mothers. They reported constant feelings of sadness, worry, and emotional distress over their sibling's illness. The degree of jealousy, anger, and competition experienced toward the sick sibling varied; however, all of the well children felt a need to minimize these feelings. Minimizing jealousy can be observed in the following statement by a 12-year-old boy who talked about his jealousy toward his younger brother with diabetes:

I often feel jealous because he gets more time from my mom. They check on him at night . . . before they go to bed and check on him in the morning. No one checks on me. I don't mind ... he needs the attention, especially when he is sad about diabetes and the needles hurt. I am glad that he gets the extra attention.

An 11 -year-old well sibling demonstrated how she minimized competitive feelings and turned them against herself when discussing her younger brother with diabetes:

When the whole family gets together sometimes I want to show I can do things too ... . like I try and show I can play something better than he can . . . when I beat hin $I$ feel really bad. I don't like it when I do that. He needs the attention more than I do. I feel bad when I beat him at things.

The degree of shame was divided between feeling no shame and often feeling shame. Children in the latter group anxiously discussed feelings that centered on not meeting up to their own internal expectations about looking after their ill brother or sister. The following example describes the internal expectations felt by a 12 -year-old boy toward his younger brother with diabetes:
My brother needs a lot of attention. Sometimes I don't play with him when I'm supposed to. I leave the house without him and play with my friends. He gets a lot of attention from any mom, when he isn't feeling well. (pause) I feel bad when I don't play with him because he is sick.

Guilt was the most prevalent affect experienced by well siblings. As an 11-year-old boy stated when he talked about his guilt toward his older sister with diabetes:

I watch my sister take needles ... she doesn't like them. It makes me feel really bad for her. I feel bad that life is so hard for her and not for me. I worry about getting diabetes and feel guilty that my sister has it and not me. When she can't go out and do things I feel bad and stay home. Sometimes I go ... [the child means that he leaves his sister and goes out with his friends] ... after I feel I shouldn't have gone. I feel really bad that my sister has diabetes and not me.

Intercorrelations among negative feelings were reviewed. A positive relationship between the degree of responsibility and the degree of jealousy ( $r$ $=.408, p<.05)$ existed. Competition was positively correlated to negative thoughts and feelings $(r=.513, p<.01)$, shame $(r=.599, p<.01)$, and guilt $(r=.524, p<.01)$. Negativity was positively correlated with shame $(r=.599, p<.01)$ and guilt $(r=.446, p<.05)$.

The correlations between the degree of affect and the standard tests were examined. The Achenbach Child Behavioral Checklist and the Reynolds Children's Depression Scale demonstrated significant correlations. From the Achenbach, withdrawal was positively associated with guilt ( $r$ $=.451, p<.05)$ and jealousy $(r=.402, p<.05)$. Negativity was positively correlated with the cluster of anxious/depressed $(r=.532, p<.01)$. Shame was negatively correlated with the cluster of social competence $\langle r=-0.621, p<.01)$ and positively associated with aggression $(r=.433, p<.05)$. The Reynolds Child's Depression Scale demonstrated a positive correlation with guilt $(r=.397, p<.05)$.

Expression of Worry About Health. Questions from the interview also examined the degree of worry well children felt toward their ill siblings' health and their own health. The majority of well children worried about their sick siblings' health. They often felt tearful or anxious about their siblings' diabetic-related health problems. They wor ried constantly about their siblings with diabetes dying. Well children also worried about their 
brothers and sisters with diabetes neglecting their health. As one 10- year-old boy related about his older brother with diabetes:

I worry about my brother not taking his needles and dying, so l watch to make sure that he takes it. When I'n away from him I worry that he takes it. I worry that he may die. One time he got really sick and could hardly move, and we took him to the hospital. My mother was really scared... [ child noticeably upset]. I was worried that he was going to die.

One-half of the children worried about their own health. Of great concern was the worry about developing diabetes. Many children discussed having symptoms similar to their brother or sister's illness. When these symptoms occurred the well children often requested a checkup to ensure that they did not have diabetes.

The three types of worry and the six negative emotional states were correlated. The only significant relationship that occurred was with guilt. There was a positive correlation between worry about the well sibling's health and the degree of guilt expressed $(r=.602, p<.01)$.

The relationship between the three types of worry and its correlation with the standard test were investigated. Significant correlations occurred between the types of worry and the Achenbach Child Behavioral Checklist. Worry about the ill sibling's health was positively correlated with withdrawal $(r=.618, p<.01)$. The cluster of worry and sensitivity on the Children's Manifest Anxiety Scale was positively correlated to worry about the ill sibling's health $(r=.472, p<.01)$ and to worry about one's own health $(r=.385, p<.05)$. There was also a positive correlation between worry about the sick sibling's health and the degree of depressive symptoms on the Reynolds Children's Depression Scale $(r=.382, p<.05)$.

Patterns of Communication. Well children's patterns of communications with parents and special friends were explored. The large majority $(n=$ 26) of well children did not discuss their feelings about diabetes with either parents or family members. Two major reasons for this were expressed. First, well siblings feared that their feelings would cause their parents to become angry. Second, well siblings worried that their feelings would have a negative effect on their parents; usually they feared it would increase their parents' worry.

Mediating Variables Affecting the Adjustment of Well Siblings. The mediating variables of ordi- nal position, gender of the well sibling, family size, and gender similarity or difference to the sick sibling were examined statistically to determine whether they influenced the well sibling's adjustment. Family size demonstrated no statistical significance in influencing the well sibling's psychological adjustment to living with a sick brother or sister. Ordinal position demonstrated one statistically significant finding. Spearman's Correlation Coefficient demonstrated that younger well siblings living with diabetic children had more difficulty on the competence scales of the Achenbach Behavioral Checklist compared with well siblings who were older $(r=.389, p<.05)$.

Gender as a mediating variable did not demonstrate any statistically significant relationships that affected the psychological adjustment of well siblings living with ill siblings. However, several relationships suggested that boys had more difficulty adjusting to living with a child with diabetes. Boys demonstrated more difficulty with the clusters of delinquency and aggression on the Achenbach Child Behavioral Checklist. Boys had lower total self-concept scores on the Piers-Harris Child's Self-Concept Scale. They also demonstrated a higher total anxiety score on the Revised Children's Manifest Anxiety Scale. In the semistructured interview, twice as many boys reported experiencing extremely guilty feelings compared with girls. During the interview it was apparent that boys were more likely to act out their aggression physically on their sick brother or sister. When children were asked what advice they would give children who recently found out that their brother or sister had diabetes, eight of the nine children who scored as projecting concern of aggression were boys.

\section{Summary}

From the results it is apparent that the well siblings were highly capable and competent in mastering their external world, yet were under psychological distress that manifested itself internally. The interviews of well siblings revealed that their pattern of competence was highly developed as an attempt to cope with the illness experience of their brothers and sisters with diabetes.

Anxiety was the major form of psychological distress experienced by well siblings. This was demonstrated by the total anxiety score on the Revised Children's Manifest Anxiety Scale, by the cluster of anxiety ranking most problematic on the Piers-Harris Children's Self-Concept Scale, and by 
anxious/depressed scores on the Achenbach Child Behavioral Checklist. The semistructured interview also produced results that supported these children's difficulties with anxious feelings. Worry seemed to be a major source of anxiety. The Revised Children's Manifest Anxiety Scale scored worry and sensitivity as the most symptomatic cause of anxiety. The positive correlation between the cluster of worry and sensitivity on the revised Children's Manifest Anxiety Scale with worry about the siblings with diabetes health $(p<.01)$ reinforced this point. The positive correlation between the degree of worry about the ill sibling's health and the degree of guilt $(p<.01)$ most likely demonstrated an increase in anxious feelings. The correlation between worry and guilt also was important in the interviews. As well children worry about their ill sibling's health, they experience more survivor guilt that is manifested as anxiety.

One-half of the children interviewed demonstrated problems with low self-concept. Most of the difficulty in self-concept came from the cluster scores around anxiety. The positive correlation between the raw scores on the Reynolds Child Depression Scale and the total self-concept and shame scores $(p s<.01)$ on the Piers-Harris Children's Self-Concept Scale highlight an important link between self-concept, shame, and depressive symptoms experienced by the well sibling. When well siblings felt they could not live up to the high standards as protective caregivers, their self-concept lowered and resulted in an increase in depressive symptoms. A major contributor to this depressive affect is shame that originated from the children's inability to live up to the expectations they had created for themselves about providing emotional and physical care for their sick brother or sister. Not living up to their high standards increased shame that would be expressed as anxiety. This explains why well siblings scored anxiety as the most problematic cluster on the Piers-Harris Children's Self-Concept Scale.

From the findings we could assume that well siblings organized their relationships with their parents around positive, caregiving roles to the exclusion of negative feelings. The negative feelings felt toward the sibling with diabetes were isolated or defended against. Well children reported discussing no negative feelings with their parents about their brother or sister with diabetes. The findings support the importance of withdrawal as a defense against discussing prohibited feelings. Withdrawal on the Achenbach Behavioral Check- list was positively correlated with the prohibited feelings of guilt $(p<.05)$, shame $(p<.05)$, jealousy $(p<.05)$, negative feelings $(p<.01)$, and worry about the ill sibling's health $(p<.01)$.

Very few well children admitted to competitive feelings with their ill siblings. From the interviews the well siblings gave the impression that competition was linked to negative affect toward the ill sibling that was defended against. This is statistically confirmed by competition's positive correlation with negativity $(p<.01)$, shame $(p<.01)$, and guilt $(p<.01)$.

The semistructured interview suggested that more than one-half of the well children experienced negative feelings toward their brothers and sisters with diabetes on a regular basis. These negative thoughts were associated with guilt and shame. In the semistructured interview negative feelings toward the ill child were significantly correlated with guilt $(p<.05)$ and shame $(p<.01)$. Theoreti cally, the above correlations could be explained in the following sequence. When well children experienced negative thoughts, actions, or feelings toward their ill brothers or sisters, these experiences were in contrast to their role as caregiver and protector, hence shame resulted. For the well sibling not meeting these internal expectations, this translated into feelings of harming the child with diabetes, which intensified guilty feelings.

Guilt was the most problematic effect experienced. There was a positive correlation between the degree of guilt and the degree of depressive symptoms $(p<.05)$. A major source of guilt came from the contradictory negative feelings and emotions felt toward the child with diabetes. The positive correlation between guilt and negative thoughts and feelings $(p<.05)$ supported this relationship. Negative thoughts and feelings toward the sibling with diabetes contradicted their strong internal feelings focused on protection. Results from the semistructured interview showed that many well children $(n=8)$ experienced guilt from their acts of aggression toward their brothers and sisters with diabetes. Children stated that they could not share any of their aggressive fantasizes or actions with their family or friends. This is supported by the positive correlation between withdrawal on the Achenbach and worry about the ill sibling's health $(p<.01)$ from the semistructured interview and by the positive correlation between worry about the ill sibling's health and guilt $(p<.01)$. In the semistructured interviews well siblings discussed having fared better than their siblings with diabetes. 
Structured tests demonstrated that well siblings were highly capable or competent in mastering their external world. Scores on the Achenbach Child Behavioral Checklist supported this conclusion. Well siblings scored high in most of the competence clusters. Children demonstrated few problems on the external problem orientation clusters of the Achenbach. Hence there were few external difficulties that would interfere with their desire to become capable children and master their external world. Competence also was seen on the cluster score of intellectual and school status on the Piers-Harris Children's Self-Concept Scale. It was ranked as most important in bolstering the child's self-concept. The semistructured interview also supported this notion. Well children demonstrated competence by the degree of knowledge they had acquired on diabetes and the degree of responsibility they took on in looking after the physical and emotional life of their sick sibling.

There was evidence that well siblings tended to internalize their difficulties and not share them with others. The Achenbach Child Behavioral Checklist demonstrated that well siblings' problems usually were internalized. The findings from the semistructured interview suggested that they worried a great deal and did not share their worries with parents and friends. These children reported experiencing difficulties in relation to the sick sibling with jealousy, negative thoughts and feelings, shame, unhappiness, and guilt and were not able to talk to parents or significant others about these emotional difficulties. The positive correlation between the degree of worry by well children about their ill sibling's health and withdrawal $(p<.01)$ and isolation $(p<.01)$ on the Achenbach supports the premise that well siblings did not share their worries or concerns with others. Several correlations support the notion that well siblings were having difficulty expressing their feelings toward significant others. The positive correlation between guilt and shame with the scale of isolation $(p<.05)$ on the Achenbach Child Behavioral Checklist suggested that these children were having a difficult time sharing feelings.

It is reasonable to infer that the nature of sibling adjustment and adaptation depended on more than illness-related stress. Hence several mediating variables were explored. This study concluded that family size, ordinal position, and gender of the well sibling, as well as gender similarity to the sibling with diabetes, were not significant in affecting well siblings' adjustment. Although gender was not statistically significant, boys did score lower on many items and scales. Male well siblings tended to have higher anxiety scores and lower self-concept scores. In part this may result from increased aggression and hostility experienced toward the ill sibling. These feelings created conflict in maintaining internal feelings of protection and caregiving toward the sibling with diabetes. In standard tests only boys demonstrated clinical/problematic scores in the aggressive range. This is reinforced in the semistructured interviews in which boys were more worried about damaging their sick brother or sister by acting out aggressively. Such aggressive feelings and actions toward their brother or sister with diabetes also may help explain why boys experienced more extreme guilty feelings. Because these findings were not statistically significant, further work needs to explore gender and its affect on the well sibling's adjustment to living with a sibling who has diabetes.

\section{Discussion}

\section{Limitations}

Because the study used volunteers from the juvenile diabetic clinic, it is difficult to determine whether this group displayed specific traits that were unique or different from other families who did not volunteer. Randomizing the sample would have been useful to make it more generalizable. Unfortunately, a large enough sample to create randomization was not available. The lack of a control group prevented comparisons of our findings with children who did not live with chronically ill siblings. It would have been interesting to compare well children's experiences with their ill brothers or sisters' experiences, to observe whether they perceived their sibling relationships differently. A comparison of well siblings from single-parent families and two-parent families would have been useful. The number of single-parent families was too small in this study to conduct a comparison.

This study isolated well siblings by investigating their emotional adaptation to the ill sibling. It would have been useful to explore how parents affect their well children's psychological response to the ill sibling. For example, the manner in which parents handle anxiety and cope with the illness may affect their well siblings' adaptation to their brothers or sisters with diabetes. Such variables as family climate, marital satisfaction, family income, and the availability of support systems may have influenced well children's relationships with their ill siblings and thus affected psychological adaptation of well 
siblings. It would be useful in future research on well children living with siblings with diabetes to investigate how these variables influence well siblings' degree of psychological stress.

It also may be useful in future research to look distinctly at how mothers and fathers influence well siblings' adaptation to a child with diabetes in the family. There was some attempt to discuss the well sibling's feelings about mother's role in the family, but fathers were not mentioned. Fathers of chronically ill children have not been studied systematically; this area needs more investigation.

The children's demand characteristics (subtle unprogrammed cues that communicate to participants something about how they should behave) were a concern in this investigation. I tried to reduce evaluation apprehension by creating a natural, open conversation in the child's home, absent from parents and other children. I was careful to look at experimenter effects and to monitor any expectations that could be translated to the well sibling. Of concern was curbing a natural tendency to show heightened concern, empathy, and curiosity toward children who demonstrated problems in adaptation with their ill siblings. Even though I tried to keep demand characteristics in mind, it is difficult to estimate what effect they may have had influencing the data.

\section{Implications for Practice and Theory}

Research investigation suggests that well siblings of brothers and sisters with diabetes are at risk of several psychological stressors. Usually health care practitioners focus on the parents and sick child. The well siblings are not given attention. This target group of well siblings easily goes undetected for several reasons: they are a group of children who present themselves as highly competent achievers; most of their problems are internally directed, which makes this population much harder to identify as being vulnerable to psychological stressors; these children have a difficult time communicating their problems to parents and friends, compounding their problems; it is easy to miss this target group because of their complementary relationship with the diabetic clinics that service parents. Well siblings who attend the clinic with their families are seen as auxiliary helpers. Such an arrangement looks adaptive because the child with diabetes can place so many burdens on parents. The well siblings are seen as helpful family nembers who alleviate some of their parent's stress.
The study demonstrates that using siblings as auxiliary support systems may support their welldeveloped sense of competence, but not address their worries, fears, and other negative enotions. It is important to identify this population of well siblings as a group that may need interventions to decrease their risk of psychological distress.

Several interventions could be implemented to assist well siblings. Psychoeducational groups designed to help parents understand the stressors of the well sibling may be helpful. The general purpose of such a group would help parents develop and share coping strategies for family issues derived from a child with diabetes. The group could help parents talk about their feelings about their ill child. By learning to tolerate their own emotions, parents may be able to communicate better and tolerate such feelings from their well children. The group could help parents develop healthy communication patterns with well siblings. However, the group must not place more burdens on parents or suggest that they are to blame for their well children's psychological stress.

Because well siblings tend to isolate feelings, a program in which they can discuss their experiences and feelings about living with a brother or sister with diabetes would be valuable. A group program would provide many of the curative components of universality and socialization that address the well children's patterns of isolation and their inability to communicate their feelings regarding their siblings with diabetes. HSW

\section{REFERENCES}

Achenbach, T. (1991). Manual for the child behavior checklist and 1991 profile. Burlington: University of Vermont Press,

Bendor, S. (1990). Anxiety and isolation in siblings of pediatric cancer patients: The need for prevention. Social Work in Health Care, 14, 17m-35.

Binger, C. (1973). Childhood leukemia: Emotional impact on siblings. In E. Anthonly \& C. Koupernik (Eds.), The child and his family: The impact of disease and death (pp. 195-209). New York: Basic Books.

Bluebond-Langer, M. (1996). In the shadow of illness: Parents and siblings of the chronically ill child. Princeton, N]: Princeton University Press.

Breslean, N., \& Prabuki, K. (1987). Siblings of disabled children: Effects of chronic stress in the family. Archives of General Psychiatry, 44, 1040 . 1046.

Brody, G., \& Stoneman, Z. (1990). Sibling relationships. In I. Segel \& G. Brody (Eds.), Methods of family research (Vol. 1). Hillsdale, NJ: Lawerence Erlbaum. 
Cairns, N., \& Clark, G. (1979). Adaptations of siblings to childhood malignancy. Journal of Pediatrics, 95, 484-487.

Carlson, J., Leviton, C., \& Mueller, M. (1993). Services to siblings: An important component of family centered practice. The Advocat, 1, 53-56.

Crain, A., Sussman, M., \& Weil, L. (1966). Family interaction, diabetes and sibling relationships. International Journal of Social Psychiatry, 12, 35-43.

Daniels, D., Miller, J., Billings, A., \& Moos, R. (1986). The psychosocial functioning of siblings of children with rheumatic disease. Journal of Pediatrics, 109, 379-383.

Daniels, D., \& Moos, R. (1987). Psychosocial risk and resistance factors among children with chronic illness, healthy siblings and healthy controls. Journal of Abrormal Child Psychology, 15.

Davies, L. (1993). Comparison of dependent and care activities for well siblings of children with cyctic fibrosis and well sibings in families without children with chronic illness. Issues in Comprehensive Pediatric Nursing, 16, 91-98.

Derouin, D., \& Jessee, P. (1996). Impact of a cluronic illness in childhood: Siblings perceptions. Issues in Comprehensive Pediatric Nursing, 19, 135-147.

Dyson, L., Edgar, E., \& Crnie, K. (1989). Psychological predictions of adjustment of siblings of developmentally disabled children. American Journal of Mental Retardation, 15.

Ferrari, M. (1984). Chronic illness: Psychosocial effects on siblings: 1. Chronically ill boys. Journal of Psychological Psychiatry, 25, 459,476.

Ferrari, M. (1987). The diabetic child and well siblings: Risks to the well child's self-concept, Children's Health Care, 15, 15-26.

Gogan, J. \& Koocher, G. (1977). Impact of childhood cancer on siblings. Health or Social Work, 2, 32-43.

lles, J. (1979). Chlordane with cancer: Healthy siblings' perception during the illness experience. Cancer Nursing, 371-377.

Kramer, R. (1981). Living with childhood cancer: Healthy sibling's perspective. Issues in Comprehensive Nursing, 1, 1327-1329.

Lavigne, J., Traisman, H., Mars, C., \& Chashoff, D. (1982). Parental perceptions of the psychosocial adjustment of children with diabetics and their siblings. Diabetes Care, 5, 420-426.

McKeever, P. (1983). Siblings of chronically ill children: A literature review with implications for research and practice. American Journal of Orthopsychiatry, 53, 208-217.

National Institutes of Health. (1995). Diabetes in America (2nd ed.). Bethesda, MD: National Diabetes Data Group.

piers, E. (1984). Piers-Harris Children's Self-Concept Scale (rev, manual), Nashville: Western Psychological Services.

Reynolds, W. (1989), Reynolds Child Depression Scale: Professional manual. Odessa, FL: Psychological Assessment Resources.
Reynolds, W., \& Richmond, B. (1985), Revised Children's Manifest Anxiety Scale. Los Angeles: Western Psychological Services.

Seligman, H. (1987). Adaptation of chlordane to a chronically ill or mentally handicapped sibling. Canadian Medical Association Journal, 136, 12491250 .

Spinnetta, J. (1981). The siblings of the child with cancer. In J. Spinetta \& D. Deasy-Spineta (Eds.), Living with childhood cancer. New York: McGraw* Hill.

Tritt, S., \& Esses, M. (1988). Psychosocial adaptation of siblings of children with chronic medical illnesses. American Journal of Orthopsychiatry, 58, $78-92$.

Wysocki, T., Huxtable, K., Linscheid, T., \& Wayne, W. (1989). Adjustment to diabetes mellitus in preschoolers and their mothers. Diabetes Care, 12, 524-529.

Zelter, L., Dolgin, M., Olle, J, Roghrnann, K., Oscar, A, Carpenter, P., Copeland, D., Mulhern, R., \& Sargent, J. (1996). Sibling adaptation to childhood cancer collaborative study: Health outcomes and siblings of children with cancer. Medical and Pediatric Oncology, 27, 98-107.

\section{ABOUT THE AUTHOR}

Colin Hollidge, PhD, LICSW, is assistant professor, Department of Social Work LOR 410, University of St. Thomas, 2115 Summit Avenue, St. Paul, MN 55105; e-mail: cfhollidge@stthomas,edu.

Accepted September 25, 2000 